\title{
Correction to: Inhibition of a cortico-thalamic circuit attenuates cue-induced reinstatement of drug-seeking behavior in "relapse prone" male rats
}

\author{
Brittany N. Kuhn ${ }^{1} \cdot$ Paolo Campus $^{2} \cdot$ Marin S. Klumpner $^{2}$ - Stephen E. Chang ${ }^{2} \cdot$ Amanda G. Iglesias $^{1}$. \\ Shelly B. Flagel ${ }^{1,2,3}$
}

Published online: 21 July 2021

(c) Springer-Verlag GmbH Germany, part of Springer Nature 2021

\section{Correction to: Psychopharmacology}

https://doi.org/10.1007/s00213-021-05894-9

After publication of this paper, the authors determined that the supplementary figures were missing in the Supplementary Information document.

The original article has been corrected.

Publisher's note Springer Nature remains neutral with regard to jurisdictional claims in published maps and institutional affiliations.

The original article can be found online at https://doi.org/10.1007/ s00213-021-05894-9.

Shelly B. Flagel

sflagel@umich.edu

1 Neuroscience Graduate Program, University of Michigan, 4137 Undergraduate Science Building, 204 Washtenaw Avenue, Ann Arbor, MI 48109, USA

2 Michigan Neuroscience Institute, University of Michigan, 205 Zina Pitcher Place, Ann Arbor, MI 48109, USA

3 Department of Psychiatry, University of Michigan, 4250 Plymouth Road, Ann Arbor, MI 48105, USA 